\title{
Analisa Drug Related Problems (DRPs) Pada Pasien Chronic Kidney Disease (CKD) Di Instalasi Rawat Inap Klinik Sari Medika Kabupaten Semarang
}

\author{
Veronika Jayaningsih"1, Poppy Diah Palupi2* \\ ${ }^{1}$ Departemen Farmasi, Klinik Sari Medika, Kabupaten Semarang, Indonesia \\ 2 Departemen Farmakologi dan Farmasi Klinik Sekolah Tinggi Ilmu Farmasi Nusaputera, Semarang, Indonesia \\ *corresponding author
}

Email: poppydiahp@gmail.com

Diterima : 17 Maret 2021

Direvisi : 27 April 2021

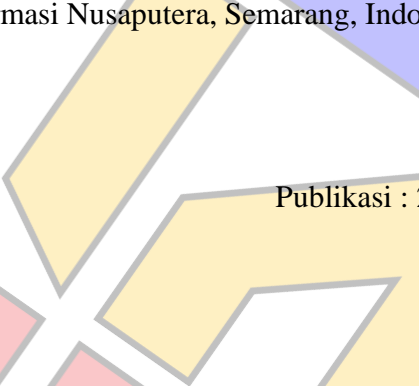

\section{Abstract}

Drug-Related Problems(DRPs) are unwanted events affecting patients related to treatment that can interfere with the success of therapy. This study aims to determine and analyze the DRPs that occur in Chronic Kidney Disease (CKD) patients in the Sari Medika Clinic, Semarang. This research is a descriptive study with retrospective design on CKD patients by taking samples using purposive sampling technique compared to the several Guidelines Pharmacotherapy Handbook 9th edition 2015, Kidney Disease Improving Global Outcomes (KDIGO), The Renal Drug Handbook Third Edition 2009, Clinical Practice Guide \& Clinical Pathway for Heart Disease, Blood Vessels 2016, and Henry Ford Health System six edition 2011. The results of the study conducted on 84 CKD patients showed there were DRPs in 66 patients: Indication without therapy (30.86\%), therapy without indication (6.17\%), sub-therapeutic dose (1.23\%), excessive drug doses (13.58\%), improper drug selection (45.68\%), and patients failing to receive drugs $(2.47 \%)$.

Keywords: DRPs, CKD, inpatients

Intisari

Drug Related Problems (DRPs) merupakan kejadian yang tidak diinginkan yang dialami oleh pasien dan berkaitan dengan pengobatan sehingga berpotensi mengganggu keberhasilan terapi. Penelitian ini bertujuan untuk mengetahui dan menganalisis DRPs yang terjadi pada pasien Chronic Kidney Disease (CKD) di instalasi rawat inap klinik Sari Medika kabupaten Semarang. Penelitian ini merupakan penelitian deskriptif dengan pengumpulan data secara retrospektif pada pasien CKD yang diperoleh dari data rekam medis. Pengambilan sampel menggunakan teknik purposive sampling. Acuan yang digunakan pada penelitian ini adalah Pharmacotherapy Handbook 9th edition 2015, Kidney Disease Improving Global Outcomes (KDIGO), The Renal Drug Handbook 3rd edition 2009, Panduan Praktik Klinis \& Clinical Pathway Penyakit Jantung, Pembuluh Darah 2016, dan Henry Ford Health System 6th edition 2011. Hasil penelitian yang dilakukan pada 84 pasien CKD menunjukkan bahwa terdapat DRPs pada 66 pasien dengan kategori yaitu indikasi tanpa terapi (30.86\%), terapi tanpa indikasi (6.17\%), dosis sub terapi (1.23\%), dosis obat berlebih (13.58\%), pemilihan obat tidak tepat (45.68\%), dan penderita gagal menerima obat $(2.47 \%)$.

Kata kunci: DRPs, CKD, pasien rawat inap 


\section{Pendahuluan}

Chronic Kidney Disease (CKD) merupakan masalah kesehatan yang umum terjadi di seluruh dunia.. CKD adalah suatu penyakit dimana fungsi organ ginjal mengalami penurunan hingga akhirnya tidak dapat menjalankan fungsi penyaringan pembuangan elektrolit tubuh, menjaga keseimbangan cairan dan zat kimia tubuh seperti sodium dan kalium di dalam darah atau produksi urine (Bahar dkk., 2014).

Berdasarkan RISKERDAS 2018, di Indonesia, angka kejadian gagal ginjal kronis sebesar $3.8 \%$. Pada stadium dini CKD, ginjal secara perlahan akan mengalami penurunan fungsi nefron yang progresif dimana laju filtrasi glomerulus masih normal atau cenderung meningkat. Pada sepertiga penderita CKD mengeluhkan gejala berupa kekurangan energi, pruritus, mengantuk, dyspnea, edema, nyeri, 2 mulut kering, kram otot, kurang nafsu makan, konsentrasi yang buruk, kulit kering, gangguan tidur, dan sembelit (Aisara dkk., 2018).

Permasalahan terkait obat atau DRPs merupakan suatu kondisi dalam penatalaksanaan terapi pasien yang berpotensi menyebabkan tidak tercapainya hasil terapi yang optimal (Furqani dkk., 2015). Adanya DRPs yang terjadi pada pasien yang menjalani rawat inap dapat mengakibatkan penurunan kualitas hidup pasien, meningkatkan biaya pengobatan yang dikeluarkan oleh pasien serta juga meningkatkan rata-rata angka kematian dan kecacatan pada pasien (Timur, 2015). Penelitian ini bertujuan untuk mengetahui dan menganalisis Drug Related Problem yang terjadi pada pasien Chronic Kidney Disease di instalasi rawat inap klinik Sari Medika kabupaten Semarang.

\section{Metode Penelitian}

\subsection{Tempat dan Waktu Penelitian}

Tempat penelitian ini dilakukan di Klinik Sari Medika Kabupaten Semarang. Waktu penelitian dilakukan pada bulan Januari-Maret 2020.

\subsection{Rancangan Penelitian}

Penelitian ini merupakan penelitian non eksperimental, yang bersifat deskriptif. Pengumpulan data dilakukan secara retrospektif pada pasien yang terdiagnosis CKD. Teknik pengambilan data yang digunakan yaitu purposive sampling.

\subsection{Kriteria inklusi dan eksklusi}

Pasien dengan kriteria inklusi sebagai berikut dimasukkan ke dalam penelitian: usia $>25$ tahun, diagnosa CKD dengan penyakit penyerta tanpa hemodialisa, sedangkan pasien dengan usia <25 tahun dan CKD dengan hemodialisa di eksklusi dalam penelitian ini.

\subsection{Analisis Data}

Data-data yang didapatkan dari rekam medis kemudian dianalisis secara deskriptif dan ditampilkan dalam bentuk tabel dan persentase.

\section{Hasil dan Pembahasan}

Sebanyak 112 pasien CKD, 84 pasien masuk kriteria inklusi dan 28 pasien masuk kriteria eksklusi. Dari data pada tabel 1 dapat diketahui 3 penyakit penyerta paling banyak pada pasien CKD adalah DM, hipertensi, dan hiperurisemia. Tingginya kadar gula dalam darah membuat ginjal harus bekerja lebih keras dalam proses penyaringan darah, sehingga mengakibatkan kerusakan ginjal (Snyder \& Pendergraph, 2005). Tingginya tekanan darah akan membuat pembuluh darah dalam ginjal tertekan, menyebabkan fungsi ginjal menurun hingga mengalami kegagalan ginjal (NIDDK, 2018).

Tabel 1. Karakteristik pasien CKD yang masuk kriteria inklusi

\begin{tabular}{ll}
\hline Karakteristik & $\mathbf{N}(\mathbf{\%})$ \\
\hline Jenis kelamin & \\
Laki-laki & $47(55.95)$ \\
Perempuan & $37(44.05)$ \\
\hline Usia (tahun) & \\
$25-44$ & $10(11.9)$ \\
$45-64$ & $47(55.95)$ \\
$65-84$ & $25(29.76)$ \\
$>85$ & $2(2.38)$ \\
\hline Penyakit penyerta & \\
\hline CKD + DM & $43(25.44)$ \\
\hline CKD + Hipertensi & $43(25.44)$ \\
CKD + hiperurisemia & $37(21.89)$ \\
CKD + dislipidemia & $24(14.20)$ \\
CKD + CHF & $12(7.10)$ \\
CKD + IHD & $10(5.92)$
\end{tabular}

CKD: chronic kidney disease, DM: diabetes melitus, IHD: Ischemic heart disease, CHF: congestive heart failure 
Dari 84 pasien yang masuk kriteria inklusi, 66 pasien mengalami DRPs dengan 81 kasus kategori DRPs dan 18 pasien yang tidak mengalami DRPs.

\section{Tabel 2. Pasien CKD dengan DRPs}

\begin{tabular}{clc}
\hline No. & \multicolumn{1}{c}{ DRPs } & N (\%) \\
\hline 1 & Indikasi tanpa terapi & $25(30.86 \%)$ \\
2 & Terapi tanpa indikasi & $5(6.17 \%)$ \\
3 & Dosis Sub terapi & $1(1.23 \%)$ \\
4 & Dosis obat berlebih & $11(13.58 \%)$ \\
5 & Pemilihan obat tidak tepat & $37(45.68 \%)$ \\
6 & Pasien gagal menerima obat & $2(2.47 \%)$ \\
\hline
\end{tabular}

\subsection{DRPs indikasi tanpa terapi}

Kejadian indikasi tanpa terapi pada pasien CKD dapat dilihat pada tabel 3.

Tabel 3. DRPs indikasi tanpa terapi

\begin{tabular}{|c|c|c|c|}
\hline No. & Kejadian DRPs & $\begin{array}{l}\text { Jumlah } \\
\text { Kasus }\end{array}$ & $\sqrt{(\%)}$ \\
\hline 1 & $\begin{array}{l}\text { Pasien hipertensi namun tidak } \\
\text { diberikan terapi obat hipertensi }\end{array}$ & 7 & \\
\hline 2 & $\begin{array}{l}\text { Pasien diabetes melitus namun } \\
\text { tidak diberikan terapi obat } \\
\text { diabetes melitus }\end{array}$ & 3 & \\
\hline 3 & $\begin{array}{l}\text { Pasien dengan kondisi } \\
\text { hipoalbumin namun tidak } \\
\text { diberikan terapi obat albumin }\end{array}$ & & \\
\hline 4 & $\begin{array}{l}\text { Pasien dengan hiperurisemia } \\
\text { namun tidak diberikan terapi } \\
\text { obat asam urat }\end{array}$ & & \\
\hline 5 & $\begin{array}{l}\text { Pasien dengan kondisi leukosit } \\
\text { tinggi namun tidak diberikan } \\
\text { terapi obat antibiotika }\end{array}$ & 3 & \\
\hline 6 & $\begin{array}{l}\text { Pasien dislipidemia namun tidak } \\
\text { diberikan terapi obat } \\
\text { dislipidemia }\end{array}$ & & \\
\hline
\end{tabular}

Persentase DRPs indikasi tanpa terapi meliputi hipertensi yaitu mencapai 7 kasus (8.64\%), diabetes 3 kasus (3.70\%), hipoalbumin 2 kasus $(2.47 \%)$, hiperurisemia 7 kasus $(8.64 \%)$, infeksi 3 kasus (3.70\%), dislipidemia 3 kasus (3.70\%). Dari data tersebut dapat diketahui 2 kasus DRPs indikasi tanpa obat dengan persentase terbesar meliputi hipertensi, hiperurisemia. Hal ini dikatakan indikasi tanpa obat karena seharusnya pasien menerima obat namun tidak diberikan terapi.

Perlunya terapi hipertensi untuk mengontrol tekanan darah pasien hingga di bawah 140/90 mmHg. Pengendalian tekanan darah dilakukan untuk mencegah terjadinya risiko penyakit kardiovaskuler di kemudian hari sehingga harus dilaksanakan pengobatan hipertensi yang terjadi pada pasien (Cokroningrat, 2017). Kasus hiperurisemia dalam darah ditentukan oleh keseimbangan antara produksi dan ekskresi. Bila keseimbangan ini terganggu maka dapat menyebabkan peningkatan kadar asam urat dalam darah atau hiperurisemia. Penderita akan cenderung mengalami pirai (gout) (Mantiri dkk., 2017). Tanpa adanya pemberian terapi obat maka kerja ginjal akan semakin berat dan akhirnya fungsi ginjal semakin mengalami penurunan secara progresif.

\subsection{DRPs terapi tanpa indikasi}

Kejadian DRPs terapi tanpa indikasi pada pasien CKD di instalasi rawat inap klinik Sari Medika kabupaten Semarang dapat dilihat pada tabel 4.

Tabel 4. DRPs terapi tanpa indikasi

\begin{tabular}{clcc}
\hline No. & \multicolumn{1}{c}{ Kejadian DRPs } & $\begin{array}{c}\text { Jumlah } \\
\text { Kasus }\end{array}$ & N(\%) \\
\hline 1 & $\begin{array}{l}\text { Pasien tanpa kondisi diabetes } \\
\text { namun diberikan terapi obat } \\
\text { anti diabetes }\end{array}$ & $3.70 \%$ \\
2 & $\begin{array}{l}\text { Pasien tanpa kondisi } \\
\text { hiperurisemia namun diberikan } \\
\text { terapi obat anti hiperurisemia }\end{array}$ & $2.47 \%$ \\
\hline
\end{tabular}

Hasil penelitian menunjukkan bahwa adanya DRPs terapi tanpa indikasi yang terjadi pada pasien tanpa kondisi diabetes atau hasil laboratorium gula yang tidak tinggi namun diberikan terapi obat diabetes sebanyak 3 kasus $(3.70 \%)$, dan pasien tanpa kondisi hiperurisemia namun diberikan terapi obat hiperurisemia sebanyak 2 kasus $(2.47 \%)$. Pemberian obat tanpa adanya indikasi di samping merugikan penderita secara finansial juga dapat merugikan penderita dengan kemungkinan munculnya efek yang tidak dikehendaki. Hal ini dapat disebabkan karena penderita menggunakan obat yang tidak sesuai dengan indikasi penyakit pada saat ini (Luntungan dkk., 2016).

\subsection{DRPs dosis sub terapi}

Dosis sub terapi adalah dosis yang diberikan lebih rendah dari dosis terapi untuk menghasilkan efek terapi yang diinginkan (Cokroningrat, 2017). Setelah dianalisis didapatkan 1 kasus dengan DRPs dosis sub terapi yaitu pada pasien dengan penyakit penyerta atrial fibrillation mendapat obat bisoprolol. Ketepatan dosis dianalisis dengan cara membandingkan dosis yang diberikan pada resep 
dengan Panduan Praktik Klinis \& Clinical Pathway Penyakit Jantung dan Pembuluh Darah (2016). Bila peresepan dosis obat-obatan berada pada rentang dosis minimal dan dosis per hari yang dianjurkan maka peresepan dikatakan tepat dosis. Menurut Panduan Praktik Klinis \& Clinical Pathway Penyakit Jantung dan Pembuluh Darah (2016), dosis bisoprolol (concor) pada atrial fibrillation yang digunakan seharusnya $5 \mathrm{mg}-10 \mathrm{mg} / \mathrm{hari}$ tetapi pada pasien hanya mendapatkan dosis $1,25 \mathrm{mg} /$ hari ini yang menyebabkan terjadinya DRPs sehingga tidak terjadinya efek terapi yang diinginkan.

\subsection{DRPs dosis obat berlebih}

Data DRPs pada dosis obat berlebih pada pasien CKD dapat dilihat pada tabel 5.

Tabel 5. DRPs dosis obat berlebih

\begin{tabular}{cccc}
\hline No. & $\begin{array}{c}\text { Nama obat generik } \\
\text { (Nama Dagang) }\end{array}$ & $\begin{array}{c}\text { Jumlah } \\
\text { Kasus }\end{array}$ & $\mathbf{N}(\%)$ \\
\hline 1 & Allopurinol (Decasurik) & 10 & $12.35 \%$ \\
2 & Metformin (Heskopaq) & 1 & $1.23 \%$ \\
\hline
\end{tabular}

Hasil penelitian menunjukkan, terdapat DRPs dosis obat berlebih pada pemberian obat allopurinol sebanyak 10 kasus $(12.35 \%)$, dan pemberian terapi obat metformin sebanyak 1 kasus (1.23\%). Allopurinol dan metformin tidak tepat dosis karena pemberian terapi obat dosisnya tidak sesuai dengan Guideline The Renal Drug Handbook 3rd edition (2009). Contoh pada pasien yang mendapat terapi obat allopurinol (decasurik®) 300 mg/hari sedangkan nilai GFR pada pasien tersebut $18,46 \mathrm{ml} / \mathrm{menit}$ dimana dosis obat terlalu tinggi Pada pasien dengan nilai GFR tersebut seharusnya $100-200 \mathrm{mg} /$ hari. Pasien yang mendapat terapi obat metformin (Heskopaq ${ }^{\circledR}$ ) dengan GFR $15.95 \mathrm{ml} /$ menit mendapat dosis 1500 mg/hari sedangkan menurut The Renal Drug Handbook 3rd edition (2009) dosis tersebut tergolong terlalu tinggi karena seharusnya adalah $500 \mathrm{mg} / \mathrm{hari}$. Akibatnya pasien mengalami kerugian seperti dosis terlalu besar, durasi terapi obat terlalu lama, interaksi obat yang terjadi akibat reaksi toksik obat, dosis obat diberikan terlalu cepat (Cokroningrat, 2017). Hal ini dapat mengakibatkan penurunan GFR pada pasien, sehingga berdampak pada kualitas hidupnya.

\subsection{DRPs Pemilihan obat tidak tepat}

Pemilihan obat tidak tepat adalah pemilihan obat yang tidak efektif berdasarkan kondisi medis sehingga tidak tepat untuk mengatasi penyakit yang diderita pasien (Meila \& Rochana, 2017).

Tabel 6. DRPs pemilihan obat tidak tepat

\begin{tabular}{clcl}
\hline No. & Kombinasi obat & Jumlah Kasus & N (\%) \\
\hline 1 & Hipertensi & 25 & $30.86 \%$ \\
2 & Diabetes Melitus & 12 & $14.82 \%$ \\
\hline
\end{tabular}

Hasil penelitian pada tabel 6 menunjukkan bahwa terdapat 37 kasus terkait DRPs pemilihan obat tidak tepat. Pada 25 kasus $(30.86 \%)$ terdapat obat hipertensi yang tidak tepat dan 12 kasus $(14.82 \%)$ pada terapi obat diabetes. Pada salah satu pasien hipertensi mendapat terapi tunggal amlodipin (golongan Calcium Channel Blocker), dimana tekanan darah pasien 170/100 mmHg. Pengobatan ini kurang tepat berdasarkan Henry Ford Health System 6th edition 2011 dimana sebaiknya menggunakan 2 kombinasi, golongan ARB atau ACEI dan dikombinasikan dengan golongan CCB atau diuretik. Pada salah satu pasien diabetes dengan gula darah sewaktu $208 \mathrm{mg} / \mathrm{dL}$ mendapat terapi gliclazide (glucodex $\left.{ }^{\circledR}\right)$ dari golongan sulfonilurea, dimana pengobatan ini kurang tepat dengan Guideline konsensus pengelolaan dan pencegahan diabetes melitus tipe 2 di Indonesia tahun 2015. Berdasarkan guideline sebaiknya diberikan terapi kombinasi yaitu golongan biguanide dengan sulfonilrea, penghambat alfa glucosidase atau lainnya. DRPs ini mengakibatkan efek terapi yang diinginkan tidak optimal, dimana seharusnya tekanan darah atau kadar gula darah yang tinggi bisa segera turun namun dikarenakan pasien mendapatkan obat tunggal saja maka tidak terjadi penurunan yang signifikan atau yang diharapkan.

\subsection{DRPs pasien gagal menerima obat}

Data DRPs gagal menerima obat pada pasien CKD dapat dilihat pada tabel 7.

Tabel 7. DRPs pasien gagal menerima obat

\begin{tabular}{clcc}
\hline No. & $\begin{array}{c}\text { Nama obat Generik } \\
\text { (Nama Dagang) }\end{array}$ & $\begin{array}{c}\text { Jumlah } \\
\text { Kasus }\end{array}$ & N (\%) \\
\hline 1 & $\mathrm{CaCO}_{3}$ & 1 & $1.24 \%$ \\
2 & Candesartan & 1 & $1.24 \%$ \\
\hline
\end{tabular}


Dari data pada tabel 7 didapatkan hasil DRPs pasien gagal menerima obat sebanyak 2 kasus, yang pertama pasien tidak mendapatkan terapi obat $\mathrm{CaCO}_{3}$ sedangkan dokter sudah meresepkan obat tersebut namun yang diberikan ke pasien adalah calcium lactate, dan permasalahan yang kedua yang tidak mendapatkan terapi obat candesartan sedangkan dokter sudah meresepkan obat tersebut namun yang diberikan ke pasien adalah amlodipin, sehingga 2 kasus tersebut masuk dalam kategori DRPs pasien gagal menerima obat. Hal tersebut disebabkan karena pasien tidak menerima obat yang sesuai yang telah diresepkan dokter sebagai akibat kesalahan medikasi (medication error).

\section{Kesimpulan}

Dari hasil penelitian dapat disimpulkan bahwa adanya DRPs pada pasien CKD di instalasi rawat inap klinik Sari Medika kabupaten Semarang sebanyak 66 pasien dengan kategori DRPs yaitu Indikasi tanpa terapi $(30.86 \%)$, terapi tanpa indikasi $(6.17 \%)$, dosis sub terapi $(1.23 \%)$, dosis obat berlebih $(13.58 \%)$, pemilihan obat tidak tepat $(45.68 \%)$, dan penderita gagal menerima obat $(2.47 \%)$.

\section{Daftar Pustaka}

Aisara, S., Azmi, S., \& Yanni, M. (2018). Gambaran Klinis Penderita Penyakit Ginjal Kronik yang Menjalani Hemodialisis di RSUP Dr. M. Djamil Padang. Jurnal Kesehatan Andalas, 7 (1), 42.

Bahar, B., Kadrianti, E., \& Asriani. (2014). Hubungan Hipertensi Dengan Kejadian Gagal Ginjal Di Rumah Sakit Ibnu Sina Makassar Periode Januari 2011- Desember 2012. Jurnal Ilmiah Kesehatan Diagnosis, 4( 6). 163-168.

Cokroningrat, S. (2017). Identifikasi Drug Related Problems (DRPs) pada Pasien Gagal Ginjal Kronik di Klinik Spesialis Ginjal dan Hipertensi Rasyida Medan Periode Januari Juni 2016. Skripsi. Universitas Sumatera Utara.

Furqani, W. H., Zazuli, Z., Nadhif, N., Saidah, S., Abdulah, R., \& Lestari, K. (2015). Drug Related Problems in the Management of Chronic Kidney Disease with Coronary Artery
Disease. Indonesian Journal of Clinical Pharmacy, 4(2), 141-150. https://doi.org/10.15416/ijcp.2015.4.2.141

Kemenkes (2018). Peran pemerintah dalam pencegahan dan pengendalian gangguan ginjal pada anak, Jakarta.

Luntungan, P., Tjitrosantoso, H., \& Yamlean, P. Y. V. (2016). Potensi Drug Related Problems (DRPs) Pada Pasien Gagal Ginjal Di Rawat Inap RSUP Prof. Dr. R. D. Kandou Manado. Pharmacon, 5(3). 23-33. DOI: https://doi.org/10.35799/pha.5.2016.129 $\underline{34}$

Mantiri, I.N. R. I., Rambert, G. I., \& Wowor, M.F. (2017). Gambaran Kadar Asam Urat pada Pasien Penyakit Ginjal Kronik Stadium 5 yang Belum Menjalani Hemodialisis. Jurnal eBiomedik (eBm), 5 (2). 1-6. DOI: https://doi.org/10.35790/ebm.5.2.2017. 17651

Meila, O., \& Rochana, H. I. (2017). Kajian Drug Related Problems (DRPs) Terhadap Pengobatan Pasien Stroke Iskemik di Rumah Sakit Pusat Otak Nasional Jakarta Periode Januari - Desember 2015. Pharmacon: Jurnal Farmasi Indonesia, 14 (2). DOI: https://doi.org/10.23917/pharmacon.v14 i2.5765

NIDDK. (2018). High Blood Pressure \& Kidney Disease | NIDDK.

Snyder, S., \& Pendergraph, B. (2005). Detection and Evaluation of Chronic Kidney Disease American Family Physician. In American Family Physician (Vol. 72, Issue 9). www.aafp.org/afpAmericanFamilyPhysician1 723

Timur, W. W. (2017). Kajian Drug Related Problem Penggunaan Antibiotik Pada Pasien Pediatrik Di Instalasi Rawat Inap Umum Daerah Kota Semarang. Jurnal Farmasi Sains dan Praktis. 3(2). 47-53. https://doi.org/10.31603/pharmacy.v3i2.1744. 